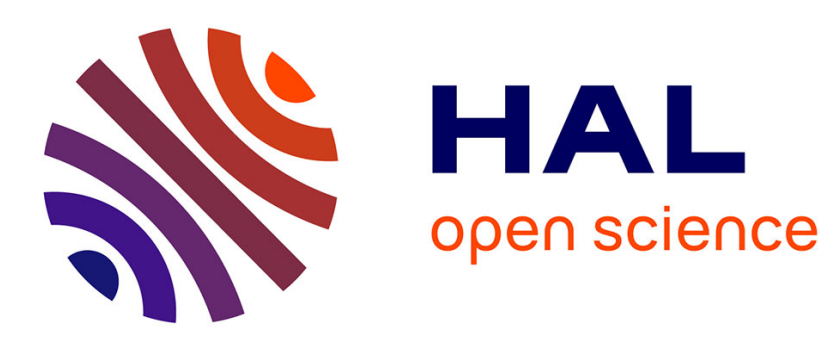

\title{
HIGH-SPEED PLASTIC DEFORMATION IN BIMETAL IN EXPLOSION WELDING
}

\author{
V. Gulbin, A. Tchudnovsky, A. Vertman
}

\section{To cite this version:}

V. Gulbin, A. Tchudnovsky, A. Vertman. HIGH-SPEED PLASTIC DEFORMATION IN BIMETAL IN EXPLOSION WELDING. Journal de Physique IV Proceedings, 1991, 01 (C3), pp.C3-241-C3-246. 10.1051/jp4:1991333 . jpa-00250475

\section{HAL Id: jpa-00250475 https://hal.science/jpa-00250475}

Submitted on 1 Jan 1991

HAL is a multi-disciplinary open access archive for the deposit and dissemination of scientific research documents, whether they are published or not. The documents may come from teaching and research institutions in France or abroad, or from public or private research centers.
L'archive ouverte pluridisciplinaire HAL, est destinée au dépôt et à la diffusion de documents scientifiques de niveau recherche, publiés ou non, émanant des établissements d'enseignement et de recherche français ou étrangers, des laboratoires publics ou privés. 
Colloque C3, supp1. au Journal de Physique III, Vol. 1, octobre 1991

\title{
HIGH-SPEED PLASTIC DEFORMATION IN BIMETAL IN EXPLOSION WELDING
}

\author{
V.N. GULBIN, A.D. TCHUDNOVSKY and A.A. VERTMAN
}

NPO NIKIMT, 127106, MOSCOW, USSR

\begin{abstract}
High-speed plastic deformation (HSPD) during explosion-welding has been studied by visioplastic methods. It has been established that in obtaining explosion-welded joint five plastic deformation zones are formed and the surface to be welded is activated prior to beginning of collision.
\end{abstract}

\section{INTRODUCTION}

At present, two most real mechanisms of joint formation process are known. The first one is the Bahrani-Crossland wave-formation model [1] - This mechanism gives a rough idea of wave formation, but does not explain the plastic deformation in the boundary layers beyond the limits of the wave-formation zone and, the more so, does not fit in with the waveless explosion welding process. The second mechanism - the mechanism of plastic deformation and formation of Hammerschmit-kreye joint [2] makes it possible to account for the emergence of high plastic deformation in near-contact layers, occurence of the cumulative jet and formation of fusions, but does not allow for wave formation. These mechanisms may well supplement each other, but, however, they are not related to the other processes occurring in explosion welding, for instance, to the plastic deformation throughout the entire volume of the article being welded, its non-uniformity and other parameters. Experimental study of such three-dimensional and extremely nonuniform deformation is very complicated. Therefore, the three-dimensional problem is usually simplified and use is made of the mechanical diagram of the two-dimensional deformation which takes place under axially symmetrical loading. Hence, the study of the explosion-welded joint formation should most reasonably be conducted with the use of visioplastic methods (coordinate grids, laminated models, etc.), which makes solution of the problem considerably easier. Here, the deformation process is three-dimensional, but follows the two-dimensional deformation scheme, and plastic deformations can with a sufficient degree of accuracy be divided into three components: longitudinal, transverse and shear deformations.

\section{RESEARCH}

The method of studying of variation of HSPD with thickness of blanks being welded together is based on the use of the coordinate grids which are drawn in the longitudinal plane of symmetry passing 
through the axis of symetry of the blanks. For studying MSPD in nearcontact layers use has been made of the laminated models method which is based on arrangement of metal laminated models in the diametrical plane perpendicular to the axis of symmetry of the pipes being welded together. In greater detail these methods are described in publications $[3-6]$ of

of high importance in studying plastic deformation of a solid deformable body are plastic and strength properties. Therefore, the following heterogenous compounds where selected as materials being studied: lead + steel (plastic and strength properties of the material of the blanks being welded are close to each other).

As a result of studying HSPD by the coordinate grid method the distribution of transverse, longitudinal and shear deformations has been obtained as functions of the wall thickness of the blanks being welded together (Figs. 1 and 2) in the steady metal flow zone with use of the method of "stopping" the joint formation process.

The analysis of the fields of final plastic deformations which characterise both qualitatively and quantitatively the strained state of metal of the blank being welded shows that at explosion-joining of the pipe blanks with relative speed of movement of the contact front Vrel $=0.73$ the longitudinal deformations EYY (Figs. $1 \mathrm{a}$ and $2 \mathrm{a}$ ) are distributed non-uniformely along the length of the source of deformation and in the zone of collision marked with point c reach maximum values. The deformations occupy the entire thickness of the wall and embrace the zone even prior to commencement of the process of deformation. The increase in the value of longitudinal tensile deformations in the direction opposite to the direction of movement of the contact front points to the intensive process of elongation of metal in the longitudinal direction.

The transverse plastic deformations $E_{\mathrm{XX}}$ (Figs. 1 and 2) extend through the entire thickness of the wall of the blank being welded and reach maximum values immediately behind the zone of collision. It should be noted that the character of distribution of these deformations in case of welding two different bimetals (material of the blanks which possess highly different and close plastic properties).

In titanium blank the transverse deformations are divided in the transverse direction along the line where $\mathrm{E}_{\mathrm{xx}}=0$ into two zones with their maximum in either of these zones. Behind the collision zone these zones are sharply localized both in the near-boundary layers and on the free surface adjacent to the charge. This points to the two-current metal flow which is not considered by any of the presented joint formation mechanisms. In the bimetal joint where the blank is made of more plastic metal-lead, the transverse deformation are of considerable importance throughout the entire thickness of the wall and are localized only in the near-contact layers of lead-steel bimetal.

The shear deformations $E_{X Y}$ (Figs. 1 and 2) are distributed nonuniformly through the thickness of the wall of the blank and through the length of the source of deformation. The character of their propagation behind the collision zone is similar for the both compounds, whereas in front of the collision zone it is different. In front of the zone of collision in the titanium-steel compound the shear deformations are divided by the zero isoline into two zones. In the near-contact zone these deformations in the longitudinal direction extend beyond the contact surface, increase when approaching the collision zone and decrease in the transverse direction only when approacting the line where $\mathrm{E}_{\mathrm{XY}}=0$. In the lead-steel joint in front of the collision zone the shear deformations are distributed extremely non-uniformly with all the isolines extending to the contact surface.

Considerable non-uniformity of transverse and shear deformations and displacements through the thickness of the wall of the blank being 

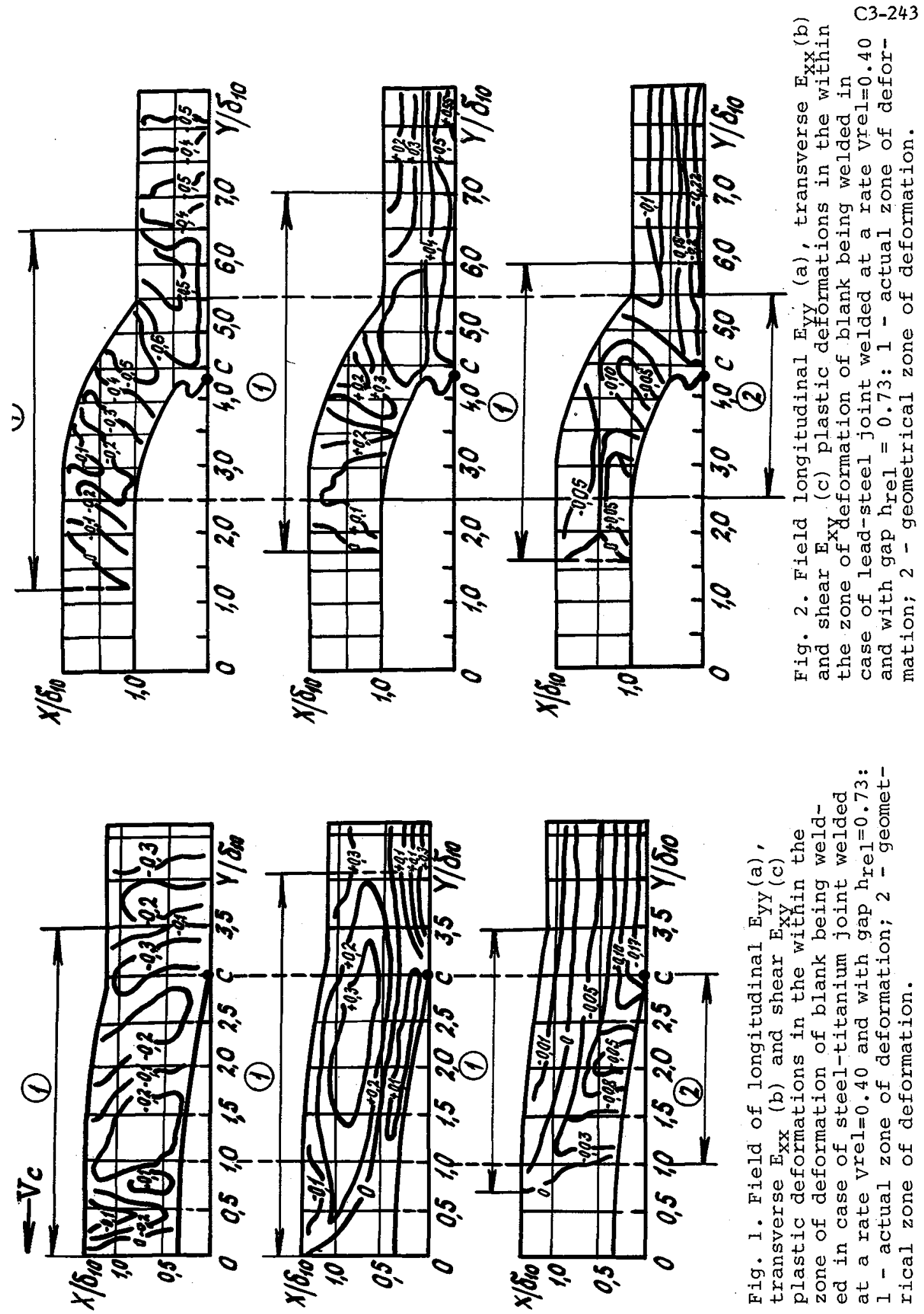
welded points to the occurence of the contact friction between the surfaces being welded. In the case of explosion welding, the contact plastic friction plays active part in the formation of explosion-welded compound, since with the help of friction the metal of the cladded blank becomes involved in the process of the joint HSPD and in the zone of collision the friction gives rise to the three-dimensional stress pattern.

Thus, the analysis of results of the experiments shows that before the beginning of the collision process in the case of explosion-welding of the pipe blanks the contact deformation is activized due to localization of plastic deformations. Under the effect of the longitudinal and shear deformations and active contact friction on the contact surface there occurs destruction of surface films (oxide, etc.) and emergence of free and active atoms of metal of the blank being welded contributing to the formation of contact and physical and chemical interaction. In the both cases the actual source of deformation enlarges the limits of the geometrical one, with its shape being different in the investigated joints. In the lead-steel joint the source of deformation of the blank being welded is convex in shape and the values of plastic deformations are higher than in the titanium-steel one.

Hence, with all other conditions being equal, for high-quality welding of the pipe blank with greater plastic and smaller strength properties metal should be subjected to less intensive plastic deformation. The presence of metal flow into the gap between the walls in the case of welding lead-steel pipes, which is in the form of a cumulative jet confirms the indefinite effect of plasticity of the original materials on the strained state of the bimetal. Formation of the plastic cumulative jet is not observed in the titanium-steel joint.

Theresults of the experiment obtained with the use of the laminated models method have made it possible to conduct the analysis of the variation of the final plastic deformation in the near-contact layers with the length of the explosion-joined blanks. It has been established that in the longitudinal direction the residual deformation of the pipe blanks can conventionally be divided into the five zones with different values of the per cent reduction $2^{\circ}$.

The first and fifth zones (Fig? 3) are the boundary ones and account for 2-5\% of the length of the blanks. The first zone is the initial one, where the wall of the blank being welded accelerates to the kinetic velocity of collision required for welding and the reduction of this blank is equal to the value of the initial gap between the walls. The degree of reduction of the blank being welded within the first zone is equal to 0.14-0.16, and the inside (cladded) pipe is not yet deformed.

In the fifth final zone $\ell^{\circ}$ reaches its maximum values both in the blank being welded $\left(\zeta^{\circ}=0.22-0.25\right)$ and in the blank being cladded. Hence, the pipe being welded in the initial zone obtains the maximum change of reduction and the blank being cladded is characterized by the maximum change of reduction in the final zone.

The second zone is the zone of welding which extends. (68-75)\% of the length of the blanks. In this zone the qualitative explosion-welded joint is formed, with the blanks being deformed here jointly and the value of per cent reduction being equal to $0.16-0.20$, i.e. the change of plastic deformation is already inconsiderable.

These sections of the welded pipes are normally used for manufacturing high-quality bimetal articles.

Regarded as the third zone should be the secondary reduction zone equal to (10-15)\% of the length of the blanks. This zone is conical in shape. The degree of reduction $\eta^{\circ}$ in this zone is a function of the diameters of the pipes in the preceding zone and amounts to 0.21-0.24. In the fourth zone whose length does not exceed (8-12)\% of the length 
Fig. 3. Distribution of per cent reduction $\eta^{\circ}$ as a function of length of titanium-steel pipe blank after explosion-welding; 1 - in welded blank; 2 - in cladded blank, 1 - joint boundary

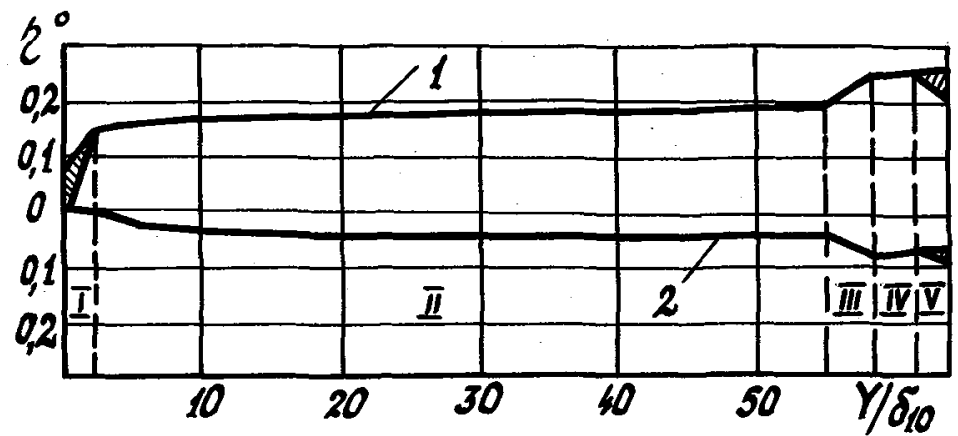

of the blanks the secondary welding zone appears with the joint reduction of the pipes being welded together. The mechanical and service properties in the third and fourth zones are unstable and, as a rule, inferior to those in the second zone. Here, as evidenced by the metallographic researches, large sections are formed in the intermediate zone with intermetallic inclusions and various defects detrimentally affecting the properties of bimetals.

The similar pattern is obtained in explosion-welding flat blanks. However, the character of deformation and the extension of the obtained zones are substantially different in character.

As a result of the analysis of the final plastic deformation as a function the length of the blanks being welded together it has been established that obtaining of bimetal joint requires formation of the initial zone where the material of the blank to be cladded becomes involved in the joining process under the effect of high HSPD of the metal. Next are the regions of joint plastic deformation where the deformation process becomes steady-state. In this case the two-dimensional deformation pattern takes place in the near-contact zones.

These zones are characterized by the formation of high-quality bimetal. In the final boundary zone the deformation process becomes unstable and the welding process decays.

The results of the study of plastic deformation by visio-plastic method make it possible to assume that non-uniformity and localization of plastic deformations on the boundary of explosion-welded joints contributes to the occurrence of the cumulative jet and contact friction which are an integral part of the explosion-welding mechanism.

In this case due to HSPD the surfaces being welded are activised prior to collision through destruction of the surface films and release of free and active atoms of the metal of the blank being welded to the surface. The deformation wave moving forward of the collision front is the destroyer of the surface films and metal activator on the blank being cladded. The wave formation process is the result of different speeds of movement of the contact front and deformation wave and therefore the length and the amplitude of the waves formed at the contact boundary depends on the difference between these speeds. This may also account for the fact that the higher the plastictty of the blank to be cladded the higher is the amplitude of the waves. The role of the accumulative jet consists also in releasing the surfaces being welded together from the remains of the surface films. 


\section{References}

1. Bahrani A.S., Black T.J., Crossland B. The Mechanics of Wave Formation in Explosive Welding. - Proc. Roy, Soc., 1967, A296, 1445. p. $123-136$.

2. M.Hammerschmidt, H.Kreye. Microstructure and mechanics of joint formation in explosive welding. Ed. by Meyers M.A., Moors I.E. Tr. from Engl. M.Metallurgiya, 1984. pp. 447-456.

3. Chichenev N.A., Kudrin A.B., Polukhin P.I. Methods of studying plastic metal working processes. M.: Metallurgiya. 1977. 308 p.

4. Solovyev V.Ya., Gulbin V.N., Ryabchikov Ye.A., Archangelskaya O.V. Studies of deformed state of cylindrical bimetal joints in highspeed pulse-cladding. Fizika i tekhnika vysokikh davleny. Kiev. Naukova Dumka, 1986. pp. 52-55.

5. Gulbin V.N., Solovyev V.Ya., Kotelkin A.V., Pominov P.P. Studies of deformed state of metal in the case of high-speed joining of pipe blanks. Obrabotka metallov davleniem. MISis. M.: Metallurgiya, 1987.

6. Gulbin V.N. Plastic deformation in explosion-welding of different metals. High Energy Rate Fabrication: $x$ International Conference, Ljubliana, Yugoslavia, Sept. 18-22, 1989. 